\title{
Chapter 22 \\ Realising Ambitious Targets and Metrics for Private-Sector Action on Climate Risks
}

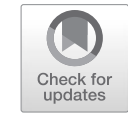

\author{
Sonja Vermeulen
}

\subsection{The Climate-Smart Agriculture Initiative of the World Business Council for Sustainable Development}

Millions of small and large businesses interact to transform agricultural inputs into the food we consume each day. Agrifood value chains involve a wide range of business interests, including suppliers, farmers, logistics companies, manufacturers and processors, retailers, caterers, financial services, and researchers. Harnessing the collective interest and input of this diverse private sector will be critical to achieving a lasting impact at global scale in climate-smart agriculture and food systems.

Large companies with an international reach are leading the way on partnerships for large-scale action on climate risks. Central to this global effort is the ClimateSmart Agriculture initiative of the World Business Council for Sustainable Development (WBCSD). WBCSD is a membership organization of companies organized into 70 national councils across the world, working together to accelerate the transition to a sustainable world. The Climate-Smart Agriculture initiative involves self-selected WBCSD member companies that are active in agrifood, in all continents, with a focus on Brazil, Ghana, India, Southeast Asia, and the United States of America. Successes in these places, which are called the 'road-test countries', may be scaled up in future.

Announced at the 2015 United Nations Climate Change Conference in Paris, the WBCSD Statement of Ambition on Climate-Smart Agriculture (WBCSD 2015) draws on multiple sources-most importantly, the United Nation's Sustainable Development Goals coupled with regional consultations with farmers, businesses, governments, civil society organizations and research institutes. The Statement of

\footnotetext{
S. Vermeulen $(\bowtie)$

Hoffmann Centre for Sustainable Resource Economy, London, UK

e-mail: sonja.vermeulen@wwf.org
} 
Ambition sets out global targets for private-sector action by 2030, under each of the three pillars of climate-smart agriculture (CSA). ${ }^{1}$

\subsection{The Three Pillars of Climate-Smart Agriculture}

Pillar 1: Productivity ambition: "Increase global food security by making $50 \%$ more nutritional food available through increased production on existing land, protecting ecosystem services and biodiversity, bringing degraded land back into productive use and reducing food loss from field to shelf." The footnotes to this WBCSD Statement explain that nutritious food means a range of macro- and micro- nutrients; that 'ecosystem services' follow the definition of the Millennium Ecosystem Assessment and, thus, include cultural as well as ecological services; and that 'food loss' is up to the point of the consumer.

Pillar 2: Climate change resilience, incomes and livelihoods ambition: "Strengthen the climate resilience of agricultural landscapes and farming communities to successfully adapt to climate change through agro-ecological approaches appropriate for all scales of farming. Invest in rural communities to deliver improved and sustainable livelihoods necessary for the future of farmers, bringing prosperity through long-term relationships based on fairness, trust, women's empowerment and the transfer of skills and knowledge."

Pillar 3: Climate change mitigation ambition: "Reduce greenhouse gas (GHG) emissions by at least $30 \%$ of annual agricultural carbon dioxide equivalent $\left(\mathrm{CO}_{2} \mathrm{e}\right)$ emissions against 2010 levels (aligned with a global 1.6 gigatonnes of carbon dioxide equivalent per year $\left(\mathrm{GtCO}_{2} \mathrm{e}\right.$ yr) reduction by 2030). A substantial portion of these reductions will also be achieved through reducing food waste up to the point of sale to the end consumer, in line with WBCSD's Action 2020 to halve food waste. Further emissions reductions will come from elimination of GHG emissions from land-use change to commercial agriculture and land restoration under the WBCSD Land Degradation Neutrality initiative."

Achievement of the targets will constitute a major contribution to the Paris Agreement as well as wider societal goals enshrined in the Sustainable Development Goals (SDGs) and global environmental agreements. Getting there will entail profound change across agrifood chains if total emissions are to fall sharply while food productivity and farming livelihoods rise. WBCSD sought CGIAR partnership to improve businesses' ability to trace, measure and monitor progress on climatesmart agriculture (Vermeulen and Frid-Nielsen 2017). The aim was not to provide a comprehensive new protocol for member companies, but rather to support monitoring and evaluation by synthesising metrics that businesses and other entities collect already.

\footnotetext{
${ }^{1}$ Note: these differ slightly from other definitions of CSA, such as that used by the Food and Agriculture Organization (FAO) of the United Nations (FAO 2013).
} 
Ahead of formal reporting by the WBCSD Climate-Smart Agriculture initiative, this chapter provides an initial analysis of progress towards the targets and the key potentials for-and obstacles to-measuring collective advances towards the global targets. These findings hopefully offer valuable early lessons to the increasing number of companies in agrifood value chains that are starting to plan and implement actions on climate risks, assisted by partners in governments, non-governmental organisations and research.

\subsection{A Simple Framework and Method for Measuring Climate-Risk Actions in Agrifood Chains}

Selection of appropriate global- and company-level indicators under each CSA pillar would try to: avoid new costs of measurement by piggy-backing on existing metrics and data collection; establish a baseline, and cover multiple subsequent years towards 2030; and provide a set of both activity and outcome indicators, linked by a testable theory of change.

The WBCSD Statement of Ambition for each CSA pillar includes both outcomes and activities towards achieving these objectives. These outcomes and activities are linked by an implicit theory of change - a hypothesis, or best bet, that the activities will deliver the outcomes (Vogel 2012). For example, the intended outcome of pillar two is to strengthen climate resilience of agricultural landscapes and farming communities. The stated activities, or best bet, to achieve this outcome include adopting agro-ecological approaches, investing in rural communities, and building long-term empowering relationships between farmers and industry.

Combining and triangulating information from WBCSD member companies with external global data sources is crucial. The WBCSD Statement of Ambition addresses the global agrifood sector, not just WBCSD members. Individual member companies will be seeking both to improve their own performance on various metrics and to track collective progress towards the global goal. They will also be looking to stimulate positive change across their own sub-sectors, as well as among governments, rural communities, consumers and other agents of change.

Among sources of global indicators, which include the World Bank, the International Fund for Agricultural Development and others, the Food and Agriculture Organization of the United Nations Statistics Division (FAOSTAT) provides global data sets on the quantity of food produced and yields (pillar 1), and direct agricultural emissions (pillar 3), but not on activities and outcomes for pillar two. Simple linear regression created business-as-usual projections and compared these with business-as-usual projections to target scenarios for 50\% more food (pillar 1), and 30\% fewer direct agricultural emissions (pillar 3). It was not possible to gauge progress relating to pillar two, since the pillar does not have a quantitative target and lacks global data to support a projection to 2030. 
When it comes to company indicators, several companies report CSA-relevant indicators within annual reports, corporate social responsibility reports and sustainability reports, or under the Global Reporting Initiative of the Carbon Disclosure Project. Companies track progress differently, in terms of which indicators are used, how the indicators are measured (e.g. absolute versus relative progress), and how far back the reporting goes. There are major gaps in data availability, both across companies and for individual companies over time. At least five companies (approximately 40\%) provided data for both 2010 and 2015 on five indicators: total waste to landfill (pillar 1), total water use (pillar 2); absolute Scope 1 emissions or Direct GHG i.e. from sources that are owned or controlled by the company, plus Scope 2 emissions or Energy Indirect GHG i.e. emissions from the consumption of purchased electricity, steam, or other sources of energy (e.g. chilled water) generated upstream from the company, and emissions intensity (pillar 3).

Current indicators at global and company levels are inadequate to provide a full picture of progress on climate-smart agriculture in line with the WBCSD definition and vision. At the company level, in particular, supplementing current data collection and reporting with additional indicators that resonate with both the SDGs and the Paris Agreement is recommended. Specific indicators are recommended in Vermeulen and Frid-Nielsen (2017).

\subsection{Snapshot of Progress Towards the WBCSD Statement of Ambition}

For pillar one on productivity, trends in global yield and production quantities from 2010 to 2014 indicate that we are on track to produce enough food to meet the WBCSD target of $50 \%$ more food by 2030 , but without the guarantee that this food will meet food security needs or sustainability criteria such as zero land expansion. From 2010 to 2014, global average production quantity and yield of important food groups (cereals, vegetables, roots and tubers, fruit, meat, and milk) increased $10.8 \%$ and $2.7 \%$ respectively. To reach the 2030 target, food production must increase by approximately $1.9 \%$ per year. However, this trajectory is not certain; it is subject to multiple risks including climate, geo-politics and markets. We do not have evidence that this food will be nutritious or accessible to poorer consumers. Moreover, there is no data available on the wider WBCSD definition of pillar one, specifically whether this increased production is on existing land (thereby improving resourceuse intensity), protects ecosystem services and biodiversity, brings degraded land back into productive use, or reduces food loss from field to shelf.

For pillar two on resilience, we know very little indeed. Neither companies nor global data sets are keeping track of the resilience and welfare of agricultural communities and landscapes under climate change. Global data sets on rural poverty can provide a metric towards the overall intended outcome of pillar two; but are not especially useful for the WBCSD CSA initiative, because they do not link to climate 
change or to private-sector activities. Company data, for example, on farmer training or contracts, is too patchy to aggregate into meaningful global statistics. Few companies report on resilience indicators, let alone in both 2010 and 2015. Similarly, FAOSTAT does not have relevant data that correspond to the WBCSD subcomponents of pillar two. For WBCSD members to demonstrate their collective progress towards building resilience in farming communities and landscapes, more companies will need to provide quantitative information on indicators that cover both activities (e.g. training; on-farm agro-ecological practices) and outcomes (e.g. women's share of assets and decisions; reductions in exposure to climate risks).

For pillar three on mitigation, the agrifood sector is already falling behind targets for agricultural and food system emissions. From 2010 to 2015, global agricultural emissions increased 3.3\% (FAOSTAT 2017). If the trend continues, the 2030 goal of $30 \%$ emissions reductions compared to 2010 will not be met; a $2.4 \%$ decrease per year is required for that. While many WBCSD member companies have demonstrated some impressive improvements in emissions intensity per unit of revenue (Vermeulen and Frid-Nielsen 2017), increasing levels of production mean that absolute emissions are rising across the global agricultural sector (see also Bennetzen et al. 2015). Deforestation-a major source of global emissions associated with agriculture that is not included in FAOSTAT data-will also contribute to some companies' emissions. Impacts of waste reduction on emissions are not yet reported.

\subsection{Challenges and Potentials for Tracking Global Private Sector Action on CSA}

This early analysis reveals that gaps in data availability, transparency and standardisation create a major obstacle to demonstrating private-sector progress towards the WBCSD Statement of Ambition on Climate-Smart Agriculture. The companies involved are not yet measuring their own performance on the targets they have set themselves, nor is this information available from global data sets.

A deeper set of issues concerns the links among shared measurement, shared management and shared accountability. Food systems are complicated, with many interconnections and feedback loops. A full discussion of private incentives to provide public goods is beyond the scope of this paper, but negatives and positives are noted briefly. The logic of collaboration to meet collective environmental and social objectives may not be compelling to individual companies, particularly if these add to operational costs. On the other hand, many companies have embraced selfregulation and voluntary collaboration as a strategy to forestall increased regulation and public activism (Haufler 2013).

These issues raise questions on possible success factors for the WBCSD members that are active in the Climate-Smart Agriculture initiative. Reflecting on progress to date, three key areas of potential might be: 
Amplifying complementary actions across a value chain: Coordinated initiatives across agrifood value chains have become a widespread approach to challenges such as the inclusion of small-scale producers in modern markets, exclusion of illegal practice, or achieving zero deforestation associated with specific commodities. Such initiatives, often linked to certification, have demonstrated positive outcomes but are not alone a sufficient solution to environmental and social challenges (DeVries et al. 2017). Climate change action faces multiple potentials for leakage, trade-offs or inequitable outcomes (Vermeulen et al. 2016), for which supply chain approaches may provide partial solutions. For a nutrient supply company, for example, helping to raise smallholder productivity might involve higher company-level emissions as more mineral fertiliser is manufactured to meet demand, but a value-chain and landscape approach might demonstrate how this is more than offset by gains in local livelihoods and resilience, coupled with reduced deforestation. For an insurance company, the returns to a crop weather insurance product might increase if issued with lower premiums for farmers who use agro-ecological approaches, climate-adapted breeds or other proven practices for climate adaptation or mitigation. Value chain initiatives can also broaden private-sector inclusion beyond multi-nationals to relevant national companies and small enterprises.

Balancing group versus individual accountability: Monitoring, reporting and accountability at the level of the value chain may be more meaningful and sensible than separate accounting by individual companies. On the other hand, targets and reporting that happen only at the group level may fail to provide incentives for action by the actual players involved, especially when the group is the whole of the global agrifood sector, as in the Statement of Ambition on Climate-Smart Agriculture. A mechanism to link individual and group accountability seems essential. The Paris Agreement itself provides one promising model, in which parties commit their individual contributions to an agreed global target. Likewise, individual companies and their alliances may find value in coordinating actions and reporting on the multiple standards and targets set by their regulators, shareholders, financiers and global agendas such as the SDGs, for reasons of efficiency and effectiveness. There may be a strong rationale to building climate-risk assessment into regular monitoring and evaluation protocols, not as standalone CSA initiatives, but through the integration of additional indicators into existing reporting and accountability on social and environmental performance.

Moving beyond dispersed local activities and outcomes to broader system-wide change: While much positive impact may come from the global sum of activities and outcomes at the level of individual farms, companies or value chains, more systemic action is likely necessary to achieve targets to reduce emissions by $30 \%$ while improving livelihoods and increasing food production by up to $50 \%$. Impacts at this scale will arise from a mix of public- and privatesector action. Recognising the importance of the system-wide enabling environment, the WBCSD Climate-Smart Agriculture initiative includes an action 
on scaling-up investment. This aims to increase CSA-friendly financial products for farmers and small businesses, and to assess options for internal carbon pricing (WBCSD 2015). Measuring and reporting of progress on this action area, and on related efforts to tackle system-wide barriers, is another key opportunity for WBCSD and other alliances. Critical to this effort will be the assessment of equity in outcomes from CSA actions at different scales (Karlsson et al. 2017). This poses the question: are actions on climate risks in the agrifood sector really delivering the intended positive outcomes for those more disadvantaged within value chains, particularly small-scale farmers and low-income consumers?

\subsection{Implications for Development}

In short, much work needs to be done-on measurement but, more importantly, on action. WBCSD member companies have rightly set out an ambitious statement of intent to address the massive climate challenges that global society faces together. Lessons from this early analysis of progress can hopefully contribute to renewed impetus to scale-up action on climate risks and bring benefits to the more disadvantaged participants in agrifood value chains globally.

\section{References}

Bennetzen E, Smith P, Porter J (2015) Decoupling of greenhouse gas emissions from global agricultural production: 1970-2050. Global Chang Biol. https://doi.org/10.1111/gcb.13120

DeVries R, Fanzo J, Mondal P et al (2017) Is voluntary certification of tropical agricultural commodities achieving sustainability goals for small-scale producers? A review of the evidence. Environ Res Lett 12:033001

FAO (2013) Climate-Smart Agriculture sourcebook. Food and Agriculture Organization of the United Nations. http://www.fao.org/3/i3325e.pdf

FAOSTAT (2017) Food and Agriculture Organization of the United Nations Statistics. http://www. fao.org/faostat

Haufler V (2013) A public role for the private sector: industry self-regulation in a global economy. Carnegie Endowment for International Peace, Washington, DC, p 160

Karlsson L, Nightingale A, Naess LO et al (2017) 'Triple wins' or 'triple faults'? Analysing policy discourses on climate-smart agriculture, CCAFS Working Paper no.197. CGIAR Research Program on Climate Change, Agriculture and Food Security (CCAFS), Copenhagen

Vermeulen S, Frid-Nielsen S (2017) Measuring progress towards the World Business Council on Sustainable Development Statement of Ambition on Climate-Smart Agriculture, CCAFS Working Paper 199. CGIAR Research Program on Climate Change, Agriculture and Food Security (CCAFS), Copenhagen https://ccafs.cgiar.org/publications/measuring-progress-towards-wbcsd-statement-ambition-climate-smart-agriculture-improving\#. WPhnEVLMyRs

Vermeulen S, Richards M, De Pinto A et al (2016) The economic advantage: assessing the value of climate-change actions in agriculture. International Fund for Agricultural Development, Rome 
Vogel I (2012) Review of the use of 'theory of change' in international development. Department for International Development, London https://www.gov.uk/dfid-research-outputs/ review-of-the-use-of-theory-of-change-in-international-development-review-report

World Business Council for Sustainable Development (2015) CSA action plan. WBCSD, Geneva http://lctpi.wbcsd.org/wp-content/uploads/2015/12/LCTPi-CSA-Action-Plan-Report.pdf

Open Access This chapter is licensed under the terms of the Creative Commons Attribution 4.0 International License (http://creativecommons.org/licenses/by/4.0/), which permits use, sharing, adaptation, distribution and reproduction in any medium or format, as long as you give appropriate credit to the original author(s) and the source, provide a link to the Creative Commons license and indicate if changes were made.

The images or other third party material in this chapter are included in the chapter's Creative Commons license, unless indicated otherwise in a credit line to the material. If material is not included in the chapter's Creative Commons license and your intended use is not permitted by statutory regulation or exceeds the permitted use, you will need to obtain permission directly from the copyright holder. 